\title{
Simultaneous Estimation of Atorvastatin, Ezetimibe and Fenofibrate in Pharmaceutical Formulation by RP-LC-PDA
}

\author{
Vishnu P. Choudhari ${ }^{1}$ and Anna Pratima Nikalje ${ }^{2 *}$
}

${ }^{1}$ Maharashtra Institute of Pharmacy, MIT Campus, Paud Road, Kothrud, Pune, 411038, MS, India

${ }^{2}$ Y.B. Chavan College of Pharmacy, Dr. Rafiq Zakaria Campus, Rauza Bagh, Aurangabad, 431001, MS, India

\begin{abstract}
A simple, rapid and precise reversed-phase liquid chromatographic method is developed for simultaneous determination of Atorvastatin, Ezetimibe and Fenofibrate in their ternary mixture of commercial pharmaceutical preparations. This method, reported first time for a ternary mixture, uses a Kromasil C18, $250 \times 4.6 \mathrm{~mm}, 5 \mu \mathrm{m}$ analytical column. Analytes were estimated by gradient elution with methanol/water at flow rate of $0.9 \mathrm{~mL} / \mathrm{min}$; the column temperature is $40^{\circ} \mathrm{C}$ and detector wavelength is $240 \mathrm{~nm}$. The sample concentrations are measured on weight basis to avoid the internal standard. The method is validated and shown to be linear. The correlation coefficients for Atorvastatin Ezetimibe and Fenofibrate are 0.9995, 0.9993 and 0.9996, respectively. The recovery values for Atorvastatin, Ezetimibe and Fenofibrate ranged from $99.7-101.1 \%, 99.8-101.3 \%$ and $99.7-101.7 \%$, respectively. The relative standard deviation for six replicates is always less than $2 \%$. This HPLC method is successfully applied to the simultaneous quantitative analysis of the title drugs in tablets.
\end{abstract}

Keywords: Atorvastatin calcium; Ezetimibe; Fenofibrate; Gradient; RP-HPLC-PDA

\section{Introduction}

Atorvastatin (AT) calcium; chemically $\left[\mathrm{R}-\left(\mathrm{R}^{*}, \mathrm{R}^{*}\right)\right]-2$-(4-fluorophenyl)$\beta, \delta$-dihydroxy-5-(1-methylethyl)-3-phenyl-4-[(phenylamino) carbonyl]$1 \mathrm{H}$-pyrrole-1-heptanoic acid, calcium salt $(2: 1)$ trihydrate, is a synthetic lipid-lowering agent. AT is an inhibitor of 3-hydroxy-3methylglutaryl-coenzyme A (HMG-CoA) reductase, the enzyme catalyzes the conversion of HMG-CoA to mevalonate an early and rate-limiting step in cholesterol biosynthesis [1,2]. AT is indicated to reduce the risk of myocardial infarction stroke and reduce the risk for revascularization procedures and angina $[3,4]$. Bioanalytical, HPLC, HPTLC, UPLC and FT- Raman Spectroscopy methods are reported for its individual determination and in combination with other drugs [5-12]. Ezetimibe (EZ); chemically (1-(4- flurophenyl)-3(R)[3(S)-(4- flurophenyl) -3-hydroxy propyl] -4(S) (4 - hydroxyphenyl) azetidin- 2- one), which belongs to a group of selective and very effective 2-azetidione cholesterol absorption inhibitors acts at the level of cholesterol entry into enterocytes [13]. Co-administration of ezetimibe with statins could provide an additional reduction in LDL cholesterol as well as total cholesterol [14]. Bioanalytical, HPLC and stability indicating HPLC methods are reported for its individual determination and in combination with other drugs [15-21].

Fenofibrate (FE); chemically 2-[4-(4-chlorobenzoyl) phenoxy]2-methyl-propanoic acid 1-methylethyl ester, is a lipid regulating agent. It is a white solid and is insoluble in water [22]. FEN is official in USP [23] and BP [24]. Stability indicating UPLC in combination with AT [11] and HPLC methods for assay and purity and an NMR method for purity [25], spectroscopy and LC method for its determination with vanpocitin in formulations [26] are reported. Structures of AT, $\mathrm{EZ}$ and $\mathrm{FE}$ are given in Figure 1.

Combination of FE with AT have additive beneficial effect in the treatment of Combined hyperlipidemia. The effects of combined therapy of FE alone on plasma adiponectin levels and insulin sensitivity were significantly greater than those of AT alone [27]. The co administration of EZ with FE offers a well tolerated, lipid management strategy for patients with mixed hyperlipidemia. The combined use of these agents provides a therapy with complementary effects to improve the atherogenic lipid profile observed for these patients [28].

The combination of AT $+\mathrm{EZ}+\mathrm{FN}$ is not official in any pharmacopoeia. So far, no HPLC method is reported for this combination. The present manuscript first time describes a LC method which is simple, rapid, precise, sensitive, selective and accurate gradient reversed phase HPLC-PDA method for the simultaneous determination of AT, EZ and FN in the tablet dosage form. During present study efforts were directed towards use of mobile phase without salt to increase column life.

\section{Material and Methods}

\section{Chemicals}

AT (purity, 99.83\%) was gifted by Litaka Pharmaceuticals, Pune (MS). EZ (purity, 99.78\%) and FN (purity, 99.8\%) were obtained
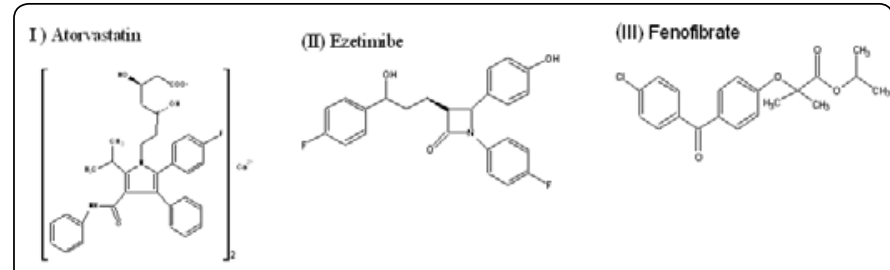

Figure 1: Representative chromatograms obtained for the mobile phase (A) placebo (B) and standard solution (C) corresponding to the 16,16 and $256 \mu \mathrm{g}$ $\mathrm{mL}$ of $\mathrm{AT}, \mathrm{EZ}$ and $\mathrm{FE}$, respectively.

*Corresponding author: Anna Pratima Nikalje, Y.B. Chavan College of Pharmacy, Dr. Rafiq Zakaria Campus, Rauza Bagh, Aurangabad, 431001, MS, India, E-Mail: ana@k.st

Received August 30, 2010; Accepted September 27, 2010 Published September 30, 2010

Citation: Choudhari VP, Nikalje AP (2010) Simultaneous Estimation of Atorvastatin, Ezetimibe and Fenofibrate in Pharmaceutical Formulation by RP-LC-PDA. Pharm Anal Acta 1:111. doi:10.4172/2153-2435.1000111

Copyright: @ 2010 Choudhari VP, et al. This is an open-access article distributed under the terms of the Creative Commons Attribution License, which permits unrestricted use, distribution, and reproduction in any medium, provided the original author and source are credited. 
Citation: Choudhari VP, Nikalje AP (2010) Simultaneous Estimation of Atorvastatin, Ezetimibe and Fenofibrate in Pharmaceutical Formulation by RPLC-PDA. Pharm Anal Acta 1:111. doi:10.4172/2153-2435.1000111

Page 2 of 5

from Ranbaxy Labs Ltd., Dewas (MP), Methanol (HPLC grade) was purchased from E. Merck (India) Ltd, Worli, Mumbai, India. Double distilled water was used throughout the experiment. Tablets were purchased from Indian market, containing FN $160 \mathrm{mg}$, AT Calcium equivalent to AT and EZ 10mg each per tablet. (Tablet Fibator EZ, Lot: 6K70712A, Sun Pharmaceuticals Ltd., Mumbai and Tablet TriTonact, Lot: LL258001, Lupin Ltd., Mumbai).

\section{Instrumentation and chromatographic conditions}

The HPLC system consisted of a binary pump (model Waters 515 HPLC pump), auto sampler (model 717 plus Auto sampler), column heater and PDA detector (Waters 2998). Data collection and analysis were performed using Empower- version 2 software. Separation was achieved on Symmetry C-18 $(250 \mathrm{~mm} \times 4.6 \mathrm{~mm}, 5.0 \mu)$ and Kromasil $\mathrm{C}-18(250 \mathrm{~mm} \times 4.6 \mathrm{~mm}, 5.0 \mu)$ columns maintained at $40^{\circ} \mathrm{C}$ using column oven. Gradient elution with methanol/water mobile phase at the flow rate of $0.7 \mathrm{~mL} / \mathrm{min}$ was carried out. The column was supported with waters symmetry C- $18,(3.9 \times 20 \mathrm{~mm}, 5.0 \mu)$ guard column. The detection was monitored at $240 \mathrm{~nm}$ and injection volume was $20 \mu \mathrm{L}$. The peak purity was checked with the photodiode array detector.

\section{Preparation of standard and sample solutions and calibration graphs}

Standard stock solution AT, EZ and FE $(1000 \mu \mathrm{g} / \mathrm{mL})$ were separately prepared in methanol. To study the linearity range of each component, serial dilutions of AT and EZ each were made from 0.5 to $32 \mu \mathrm{g} / \mathrm{mL}$ and 8 to $512 \mu \mathrm{g} / \mathrm{mL}$ of FE and injected on to column. Calibration curves were plotted as concentration of drugs versus peak area response. From the standard stock solutions, a mixed standard solution was prepared containing the analytes in the given ratio. The system suitability test was performed from six replicate injections of mixed standard solution (Table 1). Sample solution was prepared by using portion of tablet powder equivalent to one tablet. Tablet powder was transferred into $100 \mathrm{~mL}$ flasks and $80 \mathrm{~mL}$ methanol was added and sonicated for $3 \mathrm{~min}$, filtered, filter paper was washed by adding washings to flask and volume was made up with methanol. The solution was filtered through $0.45 \mu$ nylon filter. The aliquot portions of the filtrate were diluted to get final concentration of $16 \mu \mathrm{g} / \mathrm{mL}$ each of AT, EZ and $256 \mu \mathrm{g} / \mathrm{mL}$ of FE.
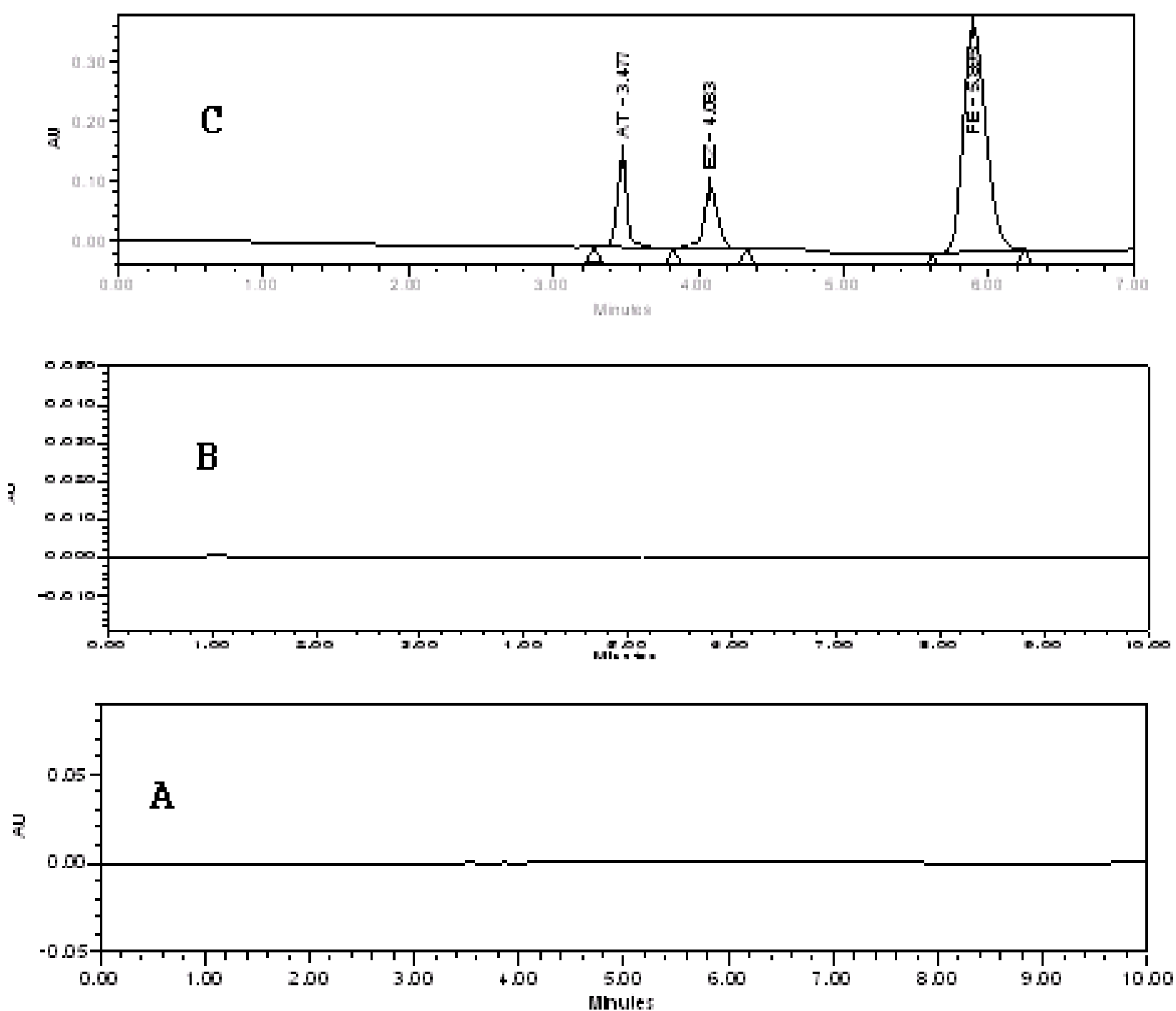

Figure 2: Representative chromatograms obtained for the mobile phase (A), placebo (B) and standard solution (C) corresponding to the 16 , 16 and $256 \mu$ g/mL of AT, EZ and FE, respectively. 


\begin{tabular}{|c|c|c|c|c|c|}
\hline \multirow[t]{3}{*}{ Drug Name } & \multicolumn{2}{|c|}{ System Suitability $(n=6)$} & \multicolumn{3}{|c|}{ Precision of the Method ${ }^{\mathrm{b}}(\mathrm{n}=3)$} \\
\hline & \multirow[t]{2}{*}{ Parameter } & \multirow[t]{2}{*}{ Value } & \multirow{2}{*}{$\begin{array}{l}\text { Actual Conc. } \\
(\mu \mathrm{g} / \mathrm{mL})\end{array}$} & \multicolumn{2}{|c|}{$\begin{array}{l}\text { Measured conc. }(\mu \mathrm{g} / \mathrm{mL}) \text {, } \\
\% \text { R.S.D }\end{array}$} \\
\hline & & & & Intra-day & Inter-day \\
\hline \multirow{3}{*}{ AT } & Plates Count & 15595 & 8 & $8.02,1.08$ & $8.03,1.85$ \\
\hline & Symmetry $^{a}$ & 1.06 & 16 & $16.08,1.21$ & $16.06,1.68$ \\
\hline & \% R.S.D. & 0.87 & 24 & $24.17,0.91$ & $24.13,1.23$ \\
\hline \multirow{4}{*}{ EZ } & Plates Count & 15875 & 8 & $8.06,0.95$ & $7.90,0.76$ \\
\hline & Resolution $^{\mathrm{a}}$ & 5.2 & 16 & $16.05,1.80$ & $16.12,1.62$ \\
\hline & Symmetrya & 1.10 & \multirow{2}{*}{24} & \multirow{2}{*}{$24.19,1.30$} & \multirow{2}{*}{$24.08,1.05$} \\
\hline & \% R.S.D. & 1.42 & & & \\
\hline \multirow{4}{*}{ FN } & Plates Count & 10304 & 128 & $128.80,0.59$ & $128.50,1.31$ \\
\hline & Resolution $^{\mathrm{a}}$ & 9.9 & 256 & $257.10,1.32$ & $256.94,1.73$ \\
\hline & Symmetry ${ }^{a}$ & 1.10 & \multirow{2}{*}{384} & \multirow{2}{*}{$384.67,0.79$} & \multirow{2}{*}{$384.98,0.88$} \\
\hline & \% R.S.D. & 0.70 & & & \\
\hline
\end{tabular}

aUSP-NF 29 section 621, pp. 2135. 'Data expressed as mean for "measured concentration" Values

Table 1: System suitability parameters and results of precision.

\begin{tabular}{|c|c|c|c|c|c|}
\hline \multirow[t]{3}{*}{ Drug Name } & \multicolumn{2}{|c|}{ System Suitability $(n=6)$} & \multicolumn{3}{|c|}{ Precision of the Method ${ }^{b}(n=3)$} \\
\hline & \multirow[t]{2}{*}{ Parameter } & \multirow[t]{2}{*}{ Value } & \multirow{2}{*}{$\begin{array}{l}\text { Actual Conc } \\
(\mu \mathrm{g} / \mathrm{mL})\end{array}$} & \multicolumn{2}{|c|}{$\begin{array}{l}\text { Measured conc. }(\mu \mathrm{g} / \mathrm{mL}) \text {, } \\
\% \text { R.S.D }\end{array}$} \\
\hline & & & & Intra-day & Inter-day \\
\hline \multirow{3}{*}{ AT } & Plates Count & 15595 & 8 & $8.02,1.08$ & $8.03,1.85$ \\
\hline & Symmetrya & 1.06 & 16 & $16.08,1.21$ & $16.06,1.68$ \\
\hline & \% R.S.D. & 0.87 & 24 & $24.17,0.91$ & $24.13,1.23$ \\
\hline \multirow{4}{*}{$E Z$} & Plates Count & 15875 & 8 & $8.06,0.95$ & $7.90,0.76$ \\
\hline & Resolution ${ }^{\mathrm{a}}$ & 5.2 & 16 & $16.05,1.80$ & $16.12,1.62$ \\
\hline & Symmetry ${ }^{\mathrm{a}}$ & 1.10 & \multirow{2}{*}{24} & \multirow{2}{*}{$24.19,1.30$} & \multirow{2}{*}{$24.08,1.05$} \\
\hline & \% R.S.D. & 1.42 & & & \\
\hline \multirow{4}{*}{ FN } & Plates Count & 10304 & 128 & $128.80,0.59$ & $128.50,1.31$ \\
\hline & Resolution ${ }^{\mathrm{a}}$ & 9.9 & 256 & $257.10,1.32$ & $256.94,1.73$ \\
\hline & Symmetry ${ }^{a}$ & 1.10 & \multirow{2}{*}{384} & \multirow{2}{*}{$384.67,0.79$} & \multirow{2}{*}{$384.98,0.88$} \\
\hline & \% R.S.D. & 0.70 & & & \\
\hline
\end{tabular}

Table 2: Results of formulation analysis and accuracy studies.

\begin{tabular}{|c|c|c|c|c|}
\hline \multirow[b]{2}{*}{ Factor } & \multirow[b]{2}{*}{ Level } & \multicolumn{3}{|c|}{ Mean $\%$ assay $(n=3), \%$ RSD of results } \\
\hline & & Atorvastatin & Ezetimibe & Fenofibrate \\
\hline \multirow{2}{*}{$\begin{array}{l}\text { Flow rate } \\
\text { (mL/min) }\end{array}$} & 0.8 & $100.6,0.79$ & $100.4,0.49$ & $100.2,0.32$ \\
\hline & 1.0 & $98.6, \quad 0.40$ & $98.6,1.25$ & $99.6,0.83$ \\
\hline \multirow{2}{*}{$\begin{array}{l}\text { Column oven } \\
\text { temperature }\left({ }^{\circ} \mathrm{C}\right)\end{array}$} & 45 & $99.1, \quad 0.82$ & $99.0, \quad 0.51$ & $99.5,1.33$ \\
\hline & 35 & 99.8, & $100.6,1.21$ & $99.9,1.18$ \\
\hline \multirow{2}{*}{$\begin{array}{l}\text { Separation } \\
\text { Column }\end{array}$} & Column la & $100.9,0.69$ & $99.6,1.10$ & $99.4, \quad 0.58$ \\
\hline & Column II & $99.8, \quad 1.53$ & $101.2,0.28$ & $100.2,1.16$ \\
\hline \multirow{2}{*}{$\begin{array}{l}\text { Measurement } \\
\text { wavelength }(\mathrm{nm})\end{array}$} & 239 & $99.35,1.53$ & $99.6, \quad 1.50$ & $99.9,0.76$ \\
\hline & 241 & $99.91,1.07$ & 98.4, & $99.8,0.59$ \\
\hline
\end{tabular}

Table 3: Result of robustness study.

\section{Method validation}

The HPLC method was validated in terms of precision, accuracy and linearity according to ICH guidelines [29]. Assay method precision was determined using nine-independent test solutions. The intermediate precision of the assay method was also evaluated. Assay method was evaluated with the recovery of the standards from excipients. Three different quantities (low, medium and high) of the authentic standards were added to pre analyzed tablet powder. The mixtures were extracted as described in Section 2.3 and were analyzed using the developed HPLC method. Linearity test solutions were prepared as described in Section 2.3. The LOD and LOQ for analytes were estimated by injecting a series of dilute solutions with known concentration. To determine the robustness of the method, the final experimental conditions were purposely altered and the results were examined. The flow rate was varied by $( \pm) 0.1 \mathrm{~mL} / \mathrm{min}$. Column temperature was varied by $( \pm) 2^{\circ} \mathrm{C}$ and effect of column from different suppliers was studied. Measurement wavelength was varied by $( \pm) 1 \mathrm{~nm}$. The stability of the drug solution was determined using the samples for short-term stability by keeping at room temperature for $12 \mathrm{~h}$ and then analyzing. The long-term stability was determined by storing at $4^{\circ} \mathrm{C}$ for 30 days. Auto-sampler stability was determined by storing the samples for $24 \mathrm{~h}$ in the auto-sampler [30].

\section{Results and Discussion}

\section{Optimization of the chromatographic conditions}

Different mobile phase compositions of methanol with water and acetonitrile with water were tried. Most of the time AT and EZ eluted with very small value of retention factor $(\mathrm{k})$ associated with long retention time $\left(t_{R}\right)$ for FE. With regards to the mobile phase acetonitrile was used as composition of the mobile phase used for determination of AT with its impurities, AT with amlodipine, AT with ramipril and aspirin, AT $+\mathrm{FE}, \mathrm{EZ}, \mathrm{AT}+\mathrm{EZ}, \mathrm{EZ}$ with simvastatin, FE and EFNO with vinpocetine [7-10,15-17,25,26]. During method development preference was given to methanol as solvent of choice. Methanol in various proportions was tired and ultimately methanol: water 80:20 resolved AT and EZ with resolution factor of 1.7 and giving suitable $k$ vale for AT which was eluted first but with peak tailing. This separation was associated with long $t_{R}$ for FN (18 min). Temperature was increased to facilitate mass exchange with the corresponding decrease of peak broadening and increase in sensibility. Various column oven temperature were tried for improving the resolution. With temp. resolution was further improved but there was slight AT peak tailing. Ultimate choice of temp. and mobile phase was $45^{\circ} \mathrm{C}$ and 73:27, methanol : water, gave satisfactory AT and EZ resolution. The optimum wavelength for detection was $240 \mathrm{~nm}$, as shown in Figure 2. Acquisition of PDA spectra showed no indigenous interfering components eluted at the retention times of the drugs. With regard to the mobile phase, an HPLC methods for AT with its impurities, AT in combinations with amlodipine, AT with ramipril and aspirin, AT + FN and AT + EZ, EZ with simvastatin [7-10,16,17] salts are described as composition of the mobile phase. The use of salts in the mobile phase, however, can affect the lifespan of the column. In order to avoid this drawback, a mobile phase containing various ratios of water and methanol was initially used. Water, however, produced a high $t_{R}$ for FN and therefore gradient was applied near about the elution time of the AT for faster elution of FN. Gradient used with respect time in minute and ratio of aqueous to organic phase was at 0.0 27/73, 3.0 27/73, 3.5 05/95, 6.0 05/95, 6.5 27/73, 7.0 27/73 was applied. The flow rate kept was $0.9 \mathrm{~mL} / \mathrm{min}$ to achieve adequate retention time of first two peaks and to achieve early elution of FN.

\section{Validation of method}

Specificity: The specificity of the HPLC method is illustrated in (Figure 2), where complete separation of AT, EZ and FN was noticed in presence of tablet placebo. In addition there was no any interference at the retention time of AT, EZ and FN in the chromatogram of tablet solution. In peak purity analysis with photo diode array detector, purity angle was always less than purity threshold for all the analytes. This shows that the peak of analytes was pure and excipients in the formulation did not interfere the analytes.

Precision and accuracy: The precision of the method was determined by performing five replicate analyses of the same working solution. The relative standard deviation (R.S.D.) obtained for AT, EZ and FN were $1.43,1.03$ and $0.72 \%$, respectively. Intra-day precision of the developed LC method was determined by preparing the tablet samples of the same batch in nine determinations with three concentrations and three replicate each. The R.S.D. of the assay results, expressed as a percentage of the label claim, was used to evaluate the method precision. The inter-day precision was also determined by assaying the tablets in triplicate per day for consecutive 3 days. The results indicated the good precision of the developed method (Table 1). Accuracy of the method was calculated 
Citation: Choudhari VP, Nikalje AP (2010) Simultaneous Estimation of Atorvastatin, Ezetimibe and Fenofibrate in Pharmaceutical Formulation by RPLC-PDA. Pharm Anal Acta 1:111. doi:10.4172/2153-2435.1000111

by recovery studies at three levels by standard addition method. The mean percentage recoveries obtained for AT, EZ and FN was 100.57, 100.77 and $100.36 \%$, respectively (Table 2 ).

Linearity and Range: For the construction of calibration curves, seven calibration standard solutions were prepared over the concentration range. Linearity was determined for AT and EZ in the range of $0.50-32 \mu \mathrm{g} / \mathrm{mL}$; and for $\mathrm{FN}, 8-512 \mu \mathrm{g} / \mathrm{mL}$. The correlation coefficient (' $r$ ') values were $>0.999(n=6)$. Typically, the regression equations for the calibration curve was found to be $\mathrm{y}=292770 \mathrm{X}$ +34689 for AT, $\mathrm{y}=3285597 \mathrm{X}+31684$ for $\mathrm{EZ}$ and $\mathrm{y}=119274 \mathrm{X}$ +24756 for FN

Sensitivity: LOD and LOQ for the procedure were performed on samples containing very low concentrations of analytes based on calibration curve method. Solutions of AT, EZ and FN were prepared in the range of 0.1 to $5 \mu \mathrm{g} / \mathrm{ml}$ and injected in triplicate. Average peak area of three analyses was plotted against concentration. LOD and LOQ were calculated by using following equations.

$$
\mathrm{LOD}=(3.3 \times \text { Syx }) / \mathrm{b} \mathrm{LOQ}=(10.0 \times \text { Syx }) / \mathrm{b}
$$

Where Syx is residual variance due to regression; $b$ is slope. The LOD and LOQ values were found to be $0.097,0.13,0.15 \mu \mathrm{g} / \mathrm{mL}$ and $0.3,0.4,0.45 \mu \mathrm{g} / \mathrm{mL}$ for AT, EZ and FN, respectively.

Solution Stability: Solution stability as described in method validation under experimental section was studied. Result of shortterm, long-term and the auto sampler stability of the AT, EZ and FN solutions were calculated form nominal concentrations and found concentration. Results of the stability studies were within the acceptable limit (98-102\%).

Application of the method to dosage forms: Two marketed formulations as described in section 2.1 were evaluated for the amount of the drugs present in the formulation. The amount of AT, $\mathrm{EZ}$ and FN estimated in 'Fibator EZ' and 'TriTonact' was in the range of $98.26-101.78,97.84-100.98$ and $98.67-101.89 \%$ respectively. None of the tablet ingredients interfered with the analyte peak (Table 2 \& Figure 2).

Robustness: Robustness of the method was investigated under a variety of conditions including changes of flow rate, column oven temperature, column form different suppliers and wavelength of measurement. The mixed standard solution is injected in five replicates and sample solution of $100 \%$ concentration is prepared and injected in triplicate for every condition and \% R.S.D. of assay was calculated for each condition. The degree of reproducibility of the results obtained as a result of small deliberate variations in the method parameters has proven that the method is robust (Table 3).

\section{Conclusions}

A simple, specific, linear, precise and accurate RP-HPLCPDA method has been developed and validated for quantitative determination of AT, EZ and FN form two tablet formulations; this is the first report of simultaneous estimation of this combination of ternary mixture. All the parameters for the three titled drugs met the criteria of ICH guidelines for method validation. The method is very simple and specific as all peaks are well separated and there is no interference by excipients peaks with total runtime of $7 \mathrm{~min}$, which makes it especially suitable for routine quality control analysis work. The method can be used for individual analysis of the titled drugs or their ternary and binary combinations.

\section{Acknowledgments}

The authors would like to thank Litaka Pharmaceuticals Ltd. and to Ranbaxy Labs Ltd., Dewas for providing gift samples of drugs. Authors are also thankful to the Principal and Management of MAEER's Maharashtra Institute of Pharmacy Pune and Maulana Azad Postgraduate and Research Center, Dr. Rafiq Zakaria Campus, Aurangabad for providing necessary facilities.

\section{References}

1. Remington (2006) The science and practice of pharmacy. Lippincott Williams \& Wilkins 1368.

2. Martindale (1999) The complete drug reference. Pharmaceutical Press 1: 1268

3. Sever PS, Poulter NR, Dahlof B, Wedel H (2005) Different Time Course for Prevention ofCoronary and Stroke Events by Atorvastatin in the AngloScandinavian Cardiac Outcomes Trial-Lipid-Lowering Arm (ASCOT-LLA) Am J Cardiol 96: 39-44.

4. Newman C, Tsai J, Szarek M, Luo D, Gibson E (2006) Comparative safety of atorvastatin $80 \mathrm{mg}$ versus $10 \mathrm{mg}$ derived from analysis of 49 completed trials in 14,236 patients. Am J Cardiol 97: 61-67.

5. Jamshidi A, Nateghi AR (2007) HPTLC Determination of Atorvastatin in Plasma Chromatographia 65: 763-766.

6. Bahrami G, Mohammadi B, Mirzaeei S, Kiani A (2005) Determination of atorvastatin in human serum by reversed-phase high-performance liquid chromatography with UV detection. J Chromatogr B 826: 41-45.

7. Ertürk S, Aktas ES, Ersoy L, Fıcıcıog־lu S (2003) J Pharm Biomed Anal 33 1017-1023.

8. Mohammadia A, Rezanour N, Dogahehc MA, Bidkorbeh FG, Hashemb M, et al (2007) J Chromatogr B 846: 215-221.

9. Panchal HJ, Suhagia BN, Patel NJ, Rathod IS, Patel BH (2009) Simultaneous Estimation of Atorvastatin Calcium, Ramipril and Aspirin in Capsule Dosage Form by RP-LC. Chromatographia 69: 91-95.

10. Kadav A, Vora DN (2008) Stability indicating UPLC method for simultaneous determination of atorvastatin, fenofibrate and their degradation products in tablets. J Pharm Biomed Anal 48: 120-126.

11. Mazurek S, Szostak R, Mazurek S, Szostak R (2009) Quantification of atorvastatin calcium in tablets by FT-Raman spectroscopy. J Pharm Biomed Anal 49: 168-172.

12. Skorda D, Kontoyannis CG (2008) Identification and quantitative determination of atorvastatin calcium polymorph in tablets using FT-Raman spectroscopy. Talanta 74: 1066-1070

13. Kerzner B, Corbelli J, Sharp S, Lipka L, Melani L, et al. (2003) J Cardiol 91: 418-424.

14. Melani L, Mills R, Hassman D, Lipetz R, Lipka L, et al. (2003) Eur. Heart J 24 717-728.

15. Sistla R, Tata VSSK, Kashyap YV, Chrasekar D, Diwan PV (2005) J Pharm Biomed Anal 39: 517-522.

16. Sonawane SS, Shirkhedkar AA, Fursule RA, Surana SJ (2006) Application of UV-Spectrophotometry and RP-HPLC for Simultaneous Determination of Atorvastatin Calcium and Ezetimibe in Pharmaceutical Dosage Form. Eurasian Journal of Analytical Chemistry 1: 31-41.

17. Kumar DA, Sujan DP, Vijayasree V, E Rao JVLNS (2009) Simultaneous Determination of Simvastatin and Ezetimibe in Tablets by HPLC. Journal of Chemistry 6: 541-544.

18. Singh S, Singh B, Bahuguna R, Wadhwa L, Saxena R (2006) Stress degradation studies on ezetimibe and development of a validated stability-indicating HPLC assay. J Pharm Biomed Anal 41: 1037-1040.

19. Doshi AS, Kachhadia PK, Joshi HS (2008) Validation of a Stability-Indicating LC Method for Assay of Ezetimibe in Tablets and for Determination of Content Uniformity. Chromatographia 67: 137-142.

20. Oswald S, Scheuch E, Cascorbid I, Siegmund W (2006) J Chromatogr B 830 143-150.

21. Shuijun L, Gangyi L, Jingying J, Xiaochuan L, Chen Y (2006) J Pharm Biomed Anal 40: 987-992.

22. United States Pharmacopoeia 32 (USP 32) (2009) United States Pharmacopeia Convention: Rockville, pp 2351.

23. The British Pharmacopoeia (2007) British Pharmacopoeial Commission London. 
Citation: Choudhari VP, Nikalje AP (2010) Simultaneous Estimation of Atorvastatin, Ezetimibe and Fenofibrate in Pharmaceutical Formulation by RPLC-PDA. Pharm Anal Acta 1:111. doi:10.4172/2153-2435.1000111

Page 5 of 5

24. Lacroix PM, Dawson BA, Sears RW, Black DB, Cyr TD, et al. (1998) Fenofibrate raw materials: HPLC methods for assay and purity and an NMR method for purity. J Pharm Biomed Anal 18: 383-402

25. El-Gindy A, Emara S, Mesbah MK, Hadad GM (2005) Spectrophotometric and liquid chromatographic determination of fenofibrate and vinpocetine and their hydrolysis products. II Farmaco 60: 425-438.

26. Koh KK, Quon MJ, Han SH, Chung WJ, Ahn JY, et al. (2005) Additive Beneficial Effects of Fenofibrate Combined With Atorvastatin in the Treatment of Combined Hyperlipidemia. J Am Coll Cardiol 45: 1649-1653.
27. Farnier M, Freeman MW, Macdonell G, Perevozskaya I, Davies MJ, et al (2005) Efficacy and safety of the coadministration of ezetimibe with fenofibrate in patients with mixed hyperlipidaemia. Eur Heart J 26: 897-905.

28. ICH (1996) ICH Q2B, Validation of Analytical Procedures: Methodology International Conference on Harmonization of Technical Requirements for Registration of Pharmaceuticals for Human Use, Geneva, Switzerland.

29. Ali H, Nazzal S (2009) Development and validation of a reversed-phase HPLC method for the simultaneous analysis of simvastatin and tocotrienols in combined dosage forms. J Pharm Biomed Anal 49: 950-956. 